\title{
Study of homeostasis of the body of pigs with the addition of asparaginates to feed
}

\author{
Irina Ziruk*, Alla Egunova, Marina Kopchekchi, Andrey Rykhlov \\ Saratov State Agrarian University named after N.I. Vavilov, Saratov, Russia
}

\begin{abstract}
The article presents the results of studying the effect of different doses of trace-elements combined with L-aspartic acid (asparaginase) on the overall homeostasis of the body of piglets. Traceelements play the main part in the composition of many organic compounds that maintain the stability of the buffer system of the colloidal state of the liquid and the osmotic pressure in the body. Scientists have proven that metal compounds in the inorganic form, in the composition of feed, are little absorbed by the body. Moreover, the increase of their doses in order to improve the level of assimilation in the body of animals, most often, causes the development of toxicosis. Therefore, the aim of the work was to study the effect of different amounts of trace-elements $(\mathrm{Zn}, \mathrm{Fe}, \mathrm{Cu}, \mathrm{Mn}, \mathrm{Co})$ in the organic form combined with L-aspartic acid on the overall homeostasis of the body of piglets. In order to achieve this goal, we conducted an experiment on large white pigs in the conditions of a pig farm in the Saratov region. We have proved that in order to normalize the overall homeostasis, as well as to increase the productive indicators of fattening piglets, it is recommended to use a mineral complex based on L-aspartic acid in the amount of $10 \%$ of the daily norm of requirements for inorganic trace elements. This topic has not been sufficiently studied in the literature to date.
\end{abstract}

\section{Introduction}

The increase of the level of profitability of industrial pork production significantly depends on improvement of the productivity of pigs by balancing the diets of trace-elements and vitamins, as well as improving various methods of breeding and improving the conditions of keeping $[4,5,7,10]$.

The results of the research conducted by many Russian and foreign scientists convincingly prove that the combination of mineral supplements in a complex for animal diets is the most rational method of introducing mineral elements. It is common to see the use of combined fodder with high nutritional value prepared according to various recipes and technological schemes $[1-3,8,11]$.

Scientists believe that the intensity of the course of metabolic or redox processes in the body can be judged reliably by the morphological and biochemical parameters of the blood and associate these parameters with the development, growth and resistance of the body to external and internal stimuli.

The search and development of effective ways to increase the use of affordable and cheap natural minerals as additives in the diets of pigs will allow us to get costeffective and harmless products [4, 6, 9, 11-13].

The use of various feed additives which contain minerals is becoming increasingly popular in animal husbandry. One of these additives is a complex of trace- elements ( $\mathrm{Zn}, \mathrm{Fe}, \mathrm{Cu}, \mathrm{Mn}, \mathrm{Co})$ with L-aspartic acid (chelated compounds, asparaginases).

The scientific research in this work is aimed at studying and analyzing the effect of various amounts of the complex of trace-elements in connection with Laspartic acid on the overall homeostasis and productivity in order to obtain high-quality products.

\section{Materials and methods}

The aim of the study is to research the effect of different amounts of mineral substances $(\mathrm{Zn}, \mathrm{Fe}, \mathrm{Cu}, \mathrm{Mn}, \mathrm{Co})$ in the organic form based on $\mathrm{L}$ - aspartic acid on the overall homeostasis of the body of piglets.

The subject of these studies is an additive consisting of a mineral complex based on L-aspartic acid "Complete complex trace-element additive in feed based on organic compounds-OMEK-7 ME" developed by the company "Bioamid", Saratov. The studied complex is a ready-made mixture consisting of five trace-elements in the form of organic compounds with L-aspartic acid, where the optimal ratio of the components is achieved.

The experiment was conducted in the conditions of a large pig-breeding complex in the Saratov region on the breed of large white piglets. In accordance with the principle of analogues, four groups of animals were formed with 15 heads in each. The pigs of the control group received the main diet of the farm. Animals of the three experimental groups (1st, 2nd and 3rd experimental groups) had an 7,5\%,10\% and $12,5 \%$ addition of

\footnotetext{
Corresponding author: iziruk@yandex.ru
} 
asparaginates to their daily feed during the whole experiment. The blood was taken before feeding the animals then it was preserved with a $5 \%$ aqueous solution of sodium citrate and studied during the whole experiment at the age of 35 days, 4 and 7 months. Morphological parameters were measured with a PCE90 Vet hematological analyzer. Biochemical parameters were measured with a BioChem - SA biochemical analyzer. The main research was carried out on the basis of the Saratov State Agrarian University. The obtained data were processed using the program "Statistica".

\section{Results and Discussion}

Morphological and biochemical parameters of blood are inextricably linked with growth, development and productivity, and also reflect the intensity of the course of metabolic processes in the body [5].

The number of red blood cells in piglets of the studied groups at the beginning of the experiment was at a stable level and amounted to $4.25 * 1012 / 1$, which corresponds to their age and physiological norm. By the age of 4 months the indicator in control animals was $5.66 \pm 0.01 * 1012 / 1$, in the 1 st experimental group $5.65 \pm 0.02 * 1012 / 1$, in the $2^{\text {nd }}-6.05 \pm 0.01 * 1012 / 1$ and in the $3^{\text {rd }}-5.76 \pm 0.01 * 1012 / 1$. The concentration of red blood cells at 7 months increased by $6.7 \%$ in the $1 \mathrm{st}$ experimental group, in the 2nd by $12.0 \%$ and in the $3 \mathrm{rd}$ by $6.6 \%$ compared to the control analogues (Fig. 1).

The average volume of red blood cells by the age of 35 days increased to $41.26 \pm 0.50$. By 7 months of age, it was $46.87 \pm 0.56 \mathrm{~mm}^{3}$, hematocrit from $27.05 \pm 0.54$ up to $29.84 \pm 0.67 \%$. The average concentration of hemoglobin in 1 red blood cell increased from $28.05 \pm 0.76$ to $31.70 \pm 0.80 \mathrm{~g} / 1$ in all experimental groups of animals, respectively. This fact indicates that the addition of asparaginates to the feed does not have a negative effect on the studied blood parameters, contributing to the maintenance of general homeostasis in the body of piglets.

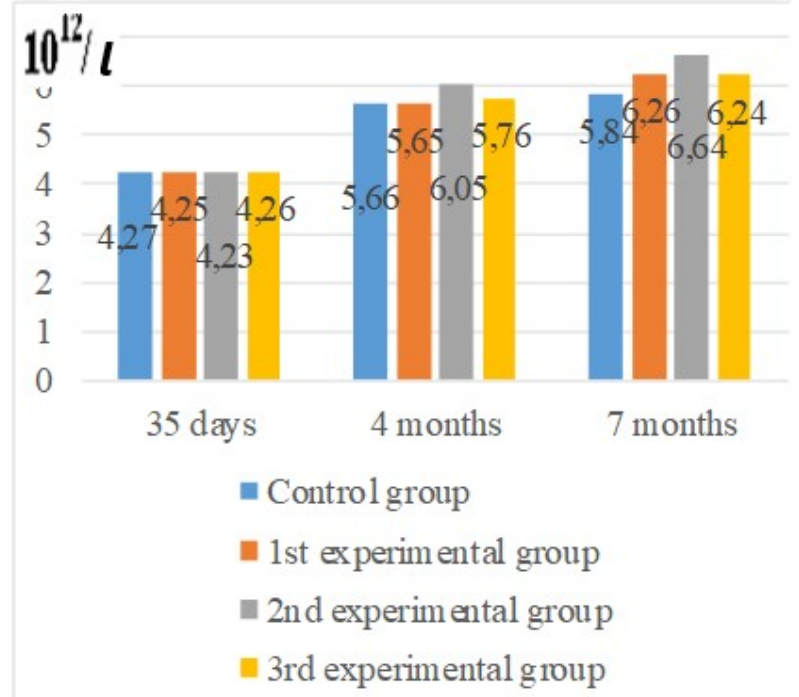

Fig. 1. The number of red blood cells in the blood of piglets, $10^{12} / 1$
The level of hemoglobin in 7-month-old piglets in the $1 \mathrm{st}, 2 \mathrm{nd}$ and 3 rd experimental groups was higher by $2.6 \%, 4.2 \%$ and $2.6 \%$, respectively, compared to the control group (Fig. 2).

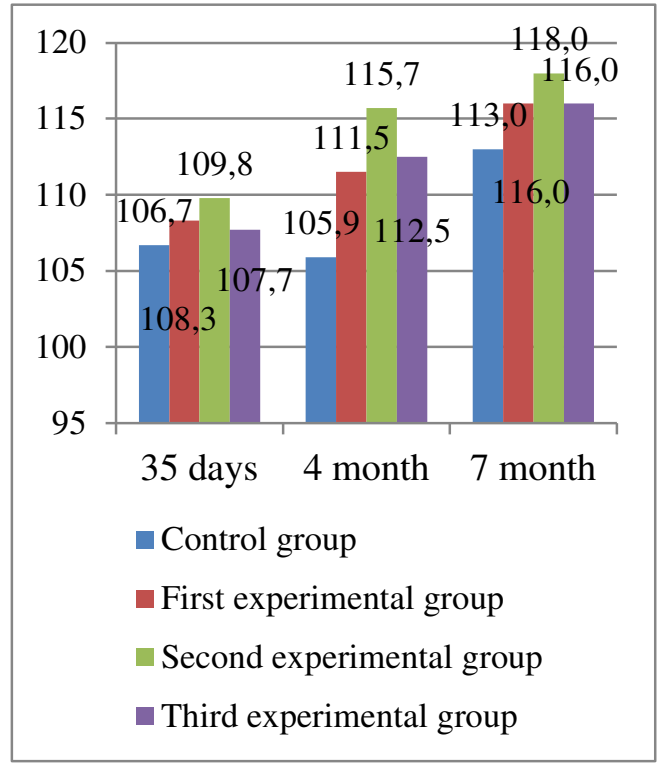

Fig. 2. Hemoglobin level in piglets, g / 1

At the beginning of the experiment, the number of white blood cells (Fig. 3) in all the studied groups was at a stable level and amounted to $13.6 * 109 / 1$. During the experimental period, the concentration of white blood cells fluctuated slightly and was within the physiological and age norm. At the end of the trial, the number of white blood cells was as follows: in the control group $13.5 \pm 0.07 * 109 / 1$, in the $1 \mathrm{st}$ experimental group $13.8 \pm 0.09 * 109 / 1$, in the 2 nd $-14.2 \pm 0.16 * 109 / 1$ and in the $3^{\text {rd }}-13.6 \pm 0.07 * 109 / 1$.

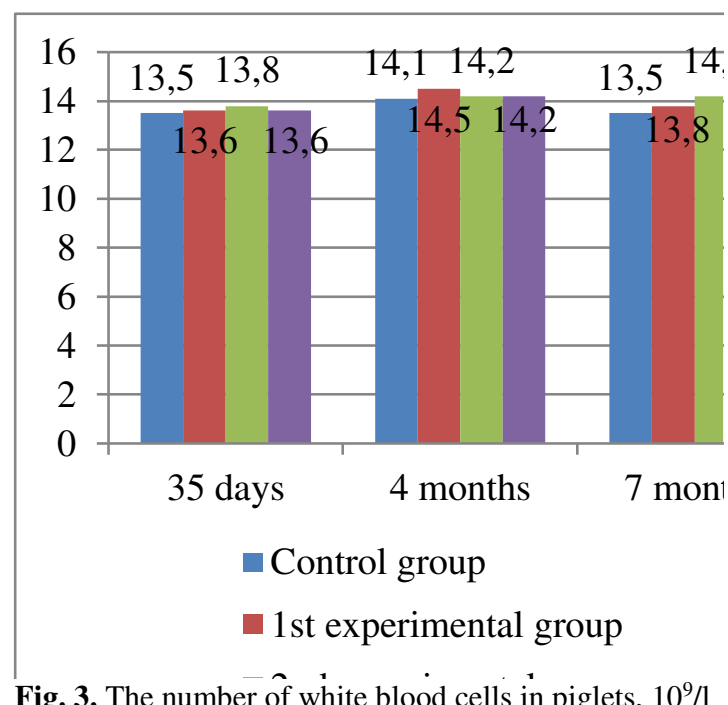

The amount of total protein in the blood serum of the piglets receiving asparaginates as part of the diet was at a higher level compared to the control (Fig. 4). The protein index in the 7-month-old control piglets was 0.57 units, in the 1st experimental group $0.62 \pm 0.005$ units, in the 3 rd $0.63 \pm 0.004$ units, respectively. The $2^{\text {nd }}$ experimental 
group's index was $0.72 \pm 0.03$ units which exceeded the results of all the studied groups.

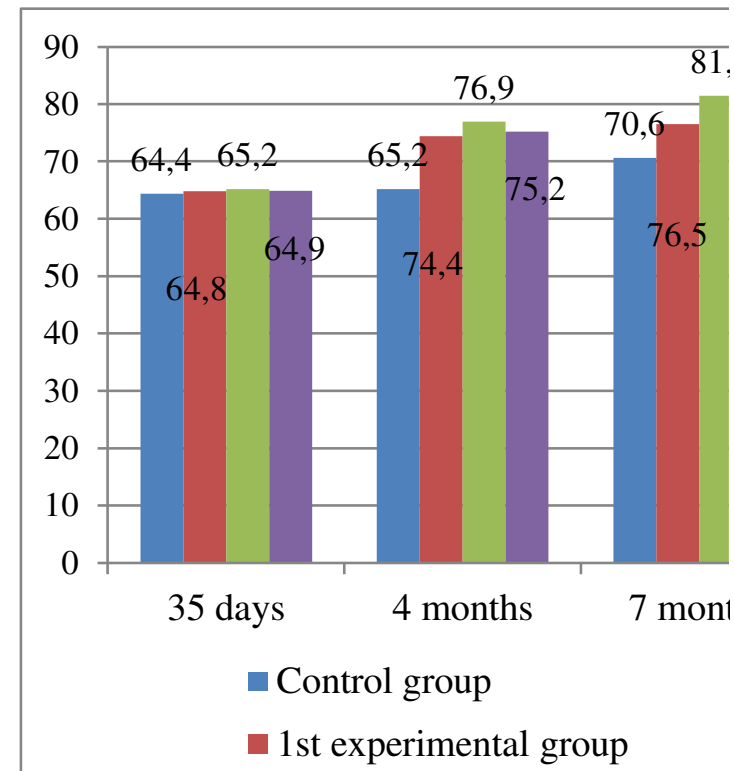

Fig. 4. Total protein concentration in the blood serum of piglets, $g / 1$

The positive trend in the increase of albumins was observed throughout the experiment (Fig. 5). The number of albumins in the 1st experimental group was higher by $10.8 \%$ and in the 3rd experimental group by $11.1 \%$ compared to intact animals. The 2 nd experimental group had the number of albumins higher by $16.0 \%$.

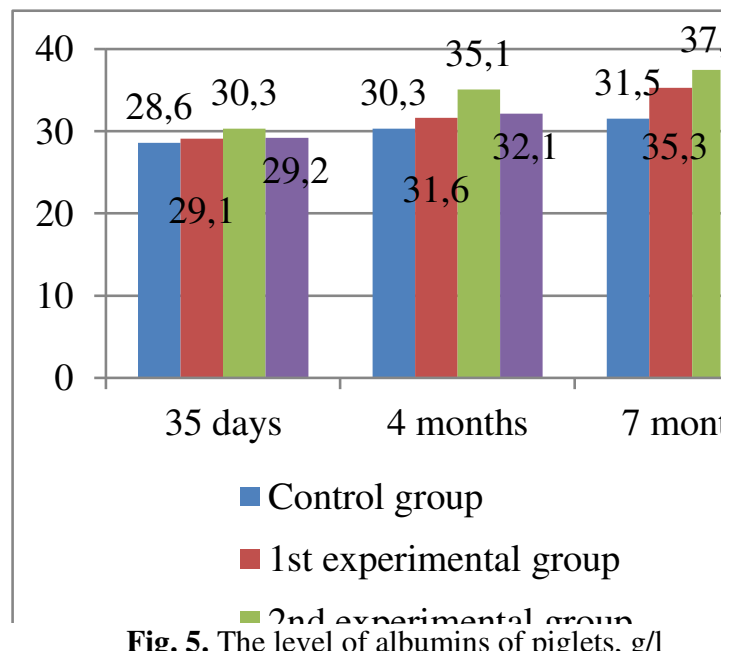

The concentration of globulins (Fig. 6) in piglets of the control group decreased by the end of the experiment in comparison with the beginning of the experiment. The $2^{\text {nd }}$ experimental group had the studied parameter exceeded the indicator of the control group by $14.1 \%$, the 1 st experimental group - by $10.2 \%$ and the $3^{\text {rd }}-$ by $10.1 \%$, respectively, at the end of the experiment.

During the entire experiment, the concentration of bilirubin in the blood serum of piglets was within their age and physiological norm.

The collected results of the AST and ALT indicators at the beginning of the experiment were $36.16 \pm 0.32 \mathrm{u} / 1$ and $40.36 \pm 0.35 \mathrm{u} / 1$, in the middle of the experiment they changed to $40.75 \pm 0.54 \mathrm{u} / 1$ and $42.17 \pm 0.60 \mathrm{u} / \mathrm{l}$, respectively. By the end of the studies, ALT and AST levels in the $2^{\text {nd }}$ experimental group of piglets were $48.65 \pm 0.77 \mathrm{u} / 1$ and $49.14 \pm 0.88 \mathrm{u} / \mathrm{l}$, which was higher than in intact animals by 5.6 and $3.93 \mathrm{u} / 1$ subsequently.

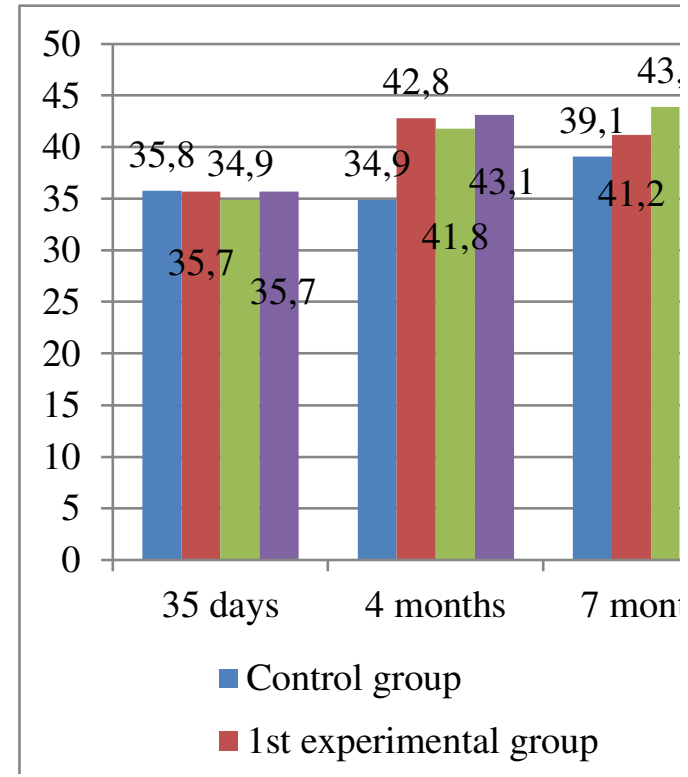

Fig. 6. The level of globulins of piglets, g/l

The bactericidal activity of blood serum (Fig. 7) increased with age in the piglets of all the studied groups. The indicator increased in the control group from $46.7 \pm 1.0$ to $47.6 \pm 1.14 \%$, in the 1 st experimental group - from $47.2 \pm 1.07$ to $49.6 \pm 1.06 \%$, in the 2 nd from $50.1 \pm 1.13$ to $50.6 \pm 1.10 \%$ and in the $3^{\text {rd }}-$ from $50.1 \pm 1.11$ to $51.7 \pm 1.13 \%$.

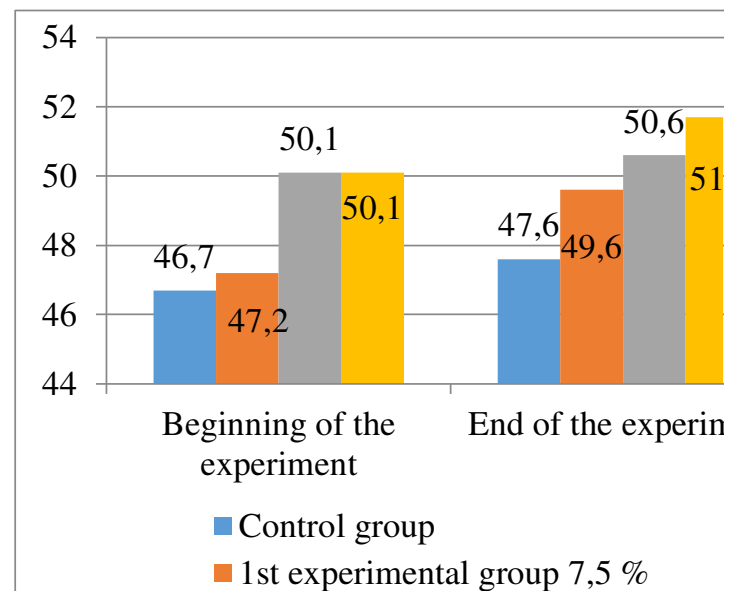

Fig. 7. The level of bactericidal activity of the blood serum of piglets, $\%$

The data that was collected on the phagocytic activity of blood serum (Fig.8) of piglets vary throughout the study. For example, at the age of 4 months, control group's animals had the analyzed indicator of $54 \pm 1.09 \%$, in the 1 st experimental group - $52 \pm 1.13 \%$, in the 2 nd

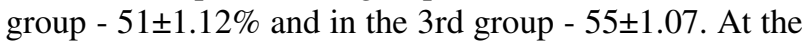
age of 7 months, the animals of the 2 nd experimental group showed an increase in the index by $5 \%$, in the 1 st and 3 rd - by $3 \%$ and $1 \%$ in comparison with the control group. 


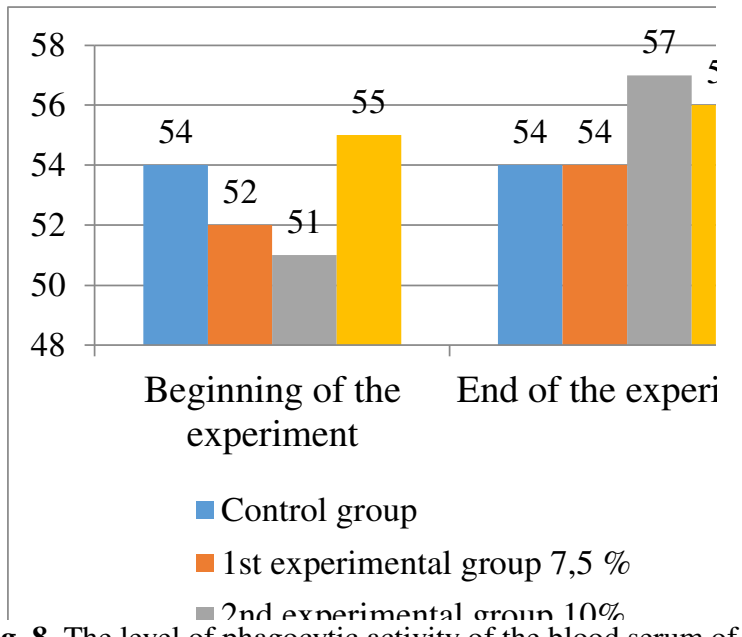

Fig. 8. The level of phagocytic activity of the blood serum of piglets, $\%$

The data on phagocytic index shows that at the beginning of the experiment control and 1st experimental group had the same results $-2.8 \pm 0.1 \%$, in the 2 nd and 3 rd $-3.0 \pm 0.3 \%$. The analyzed indicator by the end of the experiment was at a relatively equal level in the 1 st and 2 nd experimental groups, while control group had it $0.2 \%$ lower than that in the 1st and 2 nd groups and $0.1 \%$ lower than that in the 3 rd experimental group.

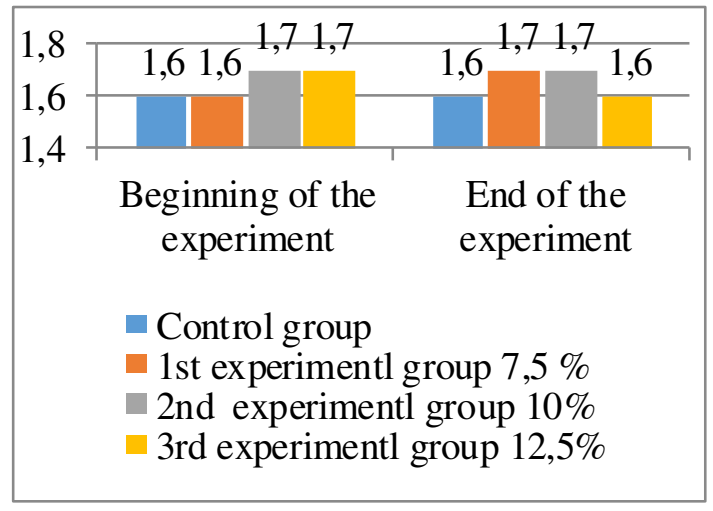

Fig. 9. Phagocytic number of blood serum of piglets

The pattern was established in the dynamics of the phagocytic number (Fig 9) which varied, as well as the phagocytic index, having the average number from $1.6 \pm 0.2$ to $1.7 \pm 0.1$.

\section{Conclusion}

It was concluded that metabolic processes and immunological reactions were more intense in the piglets of the experimental groups, who received a mineral complex (zinc, iron, copper, cobalt and manganese) based on L-aspartic acid and resulted an increase in natural resistance in the experimental animals.

This was most clearly observed in animals of the 2 nd experimental group which had mixed feed with the addition of $10 \%$ of the complex of trace-elements. Consequently, the inclusion of $10 \%$ of the amount of asparaginates in the diet was sufficient to provide the body of the piglets of the 2 nd experimental group with higher immune properties, compared to the control group and 1 st and 3rd experimental groups.

\section{References}

1. N.A. Lyubin, S.V. Dezhatkina, V.V. Akhmetova, A.Z. Mukhitov, M.E. Dezhatkin, Sh.R. Zyalalov, Russian Journal of Agricultural and SocioEconomic Sciences, 1 (97) (2020)

2. I.V. Ziruk, Influence of chelates on the dynamics of mineral accumulation in the body of pigs, Veterinarian (Kazan), 5(10-15) (2019)

3. Sh.R. Zyalalov, S.V. Dezhatkina, A.Z. Mukhitov, M.E. Dezhatkin, S.V. Merchina, L.P. Pulcherovskaya, Scientific notes of the Kazan State Academy of Veterinary Medicine named after N.E. Bauman, 3 (2020).

4. A.N. Troshkin, Some biochemical parameters of blood serum in fattening pigs receiving a mineral supplement in the form of chelate compounds with compound feed, Euro farmer, 4(5) (2006)

5. A.M. Guryanov et al., The effectiveness of using a growth-stimulating drug and special compound feeds in the diets of young pigs, Actual problems of pork production in the Russian Federation (Saratov), 34(36) (2011)

6. N.G. Fenchenko, N.I. Khairullina, I.R. Kilmetova, M.T Sabitov, I.A. Rodin, I.F. Gorlov, A.A. Mosolov, Probiotic supplement for feeding aberdeen-angus bulls: influence on the growth rate and quality of meat, International Journal of Pharmaceutical Research, 12(3) (2020)

7. P Bosi, D. Creston, L. Casini, Italian Journal of Animal Science, 1 (2002)

8. I.V. Ziruk, A.V. Egunova, M.E. Kopchekchi, V.V. Frolov, K.I. Babina, S.N. Povetkin, V.A. Karatunov, Morphometric of the pig liver under different doses of minerals in feed allowance, International Transaction Journal of Engineering, Management, \& Applied Sciences \& Technologies, 11(14) (2019)

9. D.A. Barkova, N.A. Pudovkin, V.V. Salautin, Features of free-radical oxidation of lipids in chronic liver cirrhosis, Scientific notes of Kazan State Academy of Veterinary Medicine named after N.E. Bauman, 234(2) (2018)

10. N.A. Pudovkin, Influence of the drug suiferrovit-A on the dynamics of distribution and accumulation of iron, Scientific notes of Kazan State Academy of Veterinary Medicine named after N.E. Bauman, 217(1) (2014)

11. V.N. Lopin, E.V. Lopina, S.V. Povetkin, The use of neural network classifiers for assessment of vascular remodeling in patients with arterial hypertension, Bulletin of new medical technologies, 1-2(9) (2003)

12. O.V. Molchanova, T.G. Pokrovskaya, S.V. Povetkin, K.M. Reznikov, Endothelioprotective property of the combination of the thioctic acid and rosuvastatin 
shown in the endothelial dysfunction models, Research Result: Pharmacology and Clinical Pharmacology, 2(1) (2016)
13. N.A. Pudovkin, D.A. Pyrikov, P.V. Smutnev, Ecological and physiological patterns of selenium migration within the Volga river ecosystem, $\mathrm{KnE}$ Life Sciences, 458(466) (2019) 